\title{
Effects of supplementation with Saccharomyces cerevisiae and aerobic training on physical performance of Mangalarga Marchador mares
}

\author{
Tiago Resende Garcia', Adalgiza Souza Carneiro de Rezende', Pablo Trigo², Juliano Martins \\ Santiago ${ }^{3}$, Fernando Queiroz de Almeida ${ }^{4}$, Rosângela Antunes Terra', Mayara Gonçalves \\ Fonseca ${ }^{1}$, Francisco Castejón ${ }^{2}$
}

\author{
${ }^{1}$ Universidade Federal de Minas Gerais, Escola de Veterinária, Departamento de Zootecnia, Belo Horizonte, MG, Brasil. \\ 2 Universidad de Córdoba, Córdoba, España. \\ ${ }^{3}$ Universidade Federal Rural de Pernambuco, Unidade Acadêmica de Serra Talhada, Serra Talhada, PE, Brasil. \\ ${ }^{4}$ Universidade Federal Rural do Rio de Janeiro, Instituto de Veterinária, Departamento de Medicina e Cirurgia Veterinária, Seropédica, RJ, Brasil.
}

\begin{abstract}
The objective of this study was to assess the effects of supplementation with Saccharomyces cerevisiae on the performance of Mangalarga Marchador equines and to verify the effectiveness of the aerobic training protocol adopted. The study used 14 Mangalarga Marchador mares in a completely randomized split-plot design. The plots were made up of two treatments (groups Probiotic and Control) and the split plots comprised two maximal-effort physical tests applied both before and after the six weeks of training. The animals' spirometric parameters, heart rate, and plasma lactate levels were assessed. No difference was found between the Probiotic and Control groups in any of the parameters assessed. A difference was found in the physical tests for time-to-fatigue, aerobic and anaerobic thresholds, speed at which plasma lactate levels reached 2 and 4 mmol/L, speed at which the heart rate reached $200 \mathrm{bpm}$, and the lactate level at $30 \mathrm{~min}$ of the recovery period. Supplementation with Saccharomyces cerevisiae has no effect on physical conditioning of Mangalarga Marchador mares and the aerobic training protocol adopted increases the animals' aerobic and anaerobic capacity.
\end{abstract}

Key Words: equine, nutrition, probiotic, spirometry

\section{Introduction}

Horse breeding and use have a prominent position in both developed and developing countries (CEPEA, 2006) and Brazil holds the fourth largest equine herd in the world with 5.5 million animals (FAO, 2010). In this context, the Mangalarga Marchador breed is responsible for the largest and most representative equine herd in Brazil (CEPEA, 2006) and the Brazilian Mangalarga Marchador Horsebreeders' Association (ABCCMM) is the largest equine breed association in Latin America.

Besides marcha competitions, the main competition of this breed, cavalcades, endurance rides, and functional and handling contests are part of ABCCMM's competitions. All these trials require great energy expenditure and the good performance of animals in such competitions is highly dependent on adequate nutrition associated with proper training.

The use of probiotics aiming to improve animal health has become routine, while research has shown their benefits

Received July 30, 2014 and accepted November 24, 2014

Corresponding author: adalgizavetufmg@gmail.com

http://dx.doi.org/10.1590/S1806-92902015000100004

Copyright $@ 2015$ Sociedade Brasileira de Zootecnia. This is an Open Access article distributed under the terms of the Creative Commons Attribution Non-Commercial License, which permits unrestricted non-commercial use, distribution, and reproduction in any medium, provided the original work is properly cited. in the better absorption of equine diets (Moura et al., 2009; Moura et al., 2011; and Rezende et al., 2012). These authors justify the benefits of adding probiotics to equine diets to their effect on the fermenting activity and the stabilization of the cecum-colon microbiota, which potentiates nutrient absorption.

In equine sports the physical conditioning of animals plays an important role in getting good results; it is closely related to the physical ability of the animal and the training protocol adopted. The physical conditioning can promote or maintain maximum performance, develop technical skills, minimize the occurrence of injuries, and maintain willingness and enthusiasm for exercise (Boffi, 2007).

The present study aimed to assess the effects of Saccharomyces cerevisiae supplementation and six weeks of aerobic training on the physical performance of Mangalarga Marchador mares.

\section{Material and Methods}

The experiment was carried out in the city of Rio de Janeiro/RJ, Brazil. The experimental procedures were assessed and certified by the Ethics Committee on Animal Experimentation of Universidade Federal de Minas Gerais (CETEA - UFMG), under protocol 206/2008. 
Fourteen clinically healthy non-pregnant Mangalarga Marchador mares between four and nine years-old weighing between 320 and $413 \mathrm{~kg}$ were used. The mares had never been trained. The study followed a completely randomized split-plot design. The plots were made up of two treatments (Probiotic and Control groups) with seven repetitions per treatment, while the split plots comprised two maximal-effort physical tests applied before and after the six weeks of training.

The animals were housed in individual masonry stalls with feeding troughs for hay and concentrate, and drinking troughs for free access to water. The horses were fed a diet made up of coastcross (Cynodon dactylon) hay and commercial concentrate (Itambé ${ }^{\circledR}$ Expander Atleta feed). The mares were weighed at the beginning of the experimental period and every week afterwards. At each weighing, the daily diet was calculated as $2.5 \%$ of the live weight of each animal, which represented the dry matter intake until the next weighting. The amount of concentrate provided represented $50 \%$ of that value. These values were determined for horses in moderate work, according to the NRC (2007). The concentrate feed was split into three daily portions supplied at $06.00 \mathrm{~h}, 12.00 \mathrm{~h}$, and $18.00 \mathrm{~h}$, while hay was split into two portions supplied at $08.00 \mathrm{~h}$ and $19.00 \mathrm{~h}$. Mineral salt was freely available.

The experimental trial was divided into two phases. In the first phase, which lasted 15 days, the mares adapted to the facilities, handling, and to the treadmill exercises $\left(\right.$ Galloper Sahinco $^{\circledR}$ ) wearing a spirometry mask (MetaVet 1.0 - Cortex Biophysik), and to the automated walker $\left(\right.$ Sahinco $^{\circledR}$ ). The first treadmill maximal ergospiromety test was applied at the end of the first phase. In the second phase, which lasted 42 days, the mares underwent aerobic training and the Probiotic group, besides being fed the standard diet, started to receive $20 \mathrm{~g}$ Saccharomyces cerevisiae (Biosaf Sc $47^{\circledR}$ - Lesaffre Feed Additives) daily (minimum of $1.9 \times$ $10^{9} \mathrm{cfu} / \mathrm{g}$ ) and also the concentrate for the first time.

The mares trained for six weeks, Mondays through Saturdays, alternating the exercise on the treadmill and the automated walker. The training protocol on the treadmill consisted of an initial 10-min warm-up period, comprising five minutes of walking $(1.6 \mathrm{~m} / \mathrm{s})$ and five minutes of marching $(3.5 \mathrm{~m} / \mathrm{s})$. Next, the treadmill was sloped at $3^{\circ}$ and the animals marched for $30 \mathrm{~min}$ at a specific speed for each animal that corresponded to $80 \%$ of their aerobic threshold determined in the first ergospirometry test, ranging from 3.6 to $4.4 \mathrm{~m} / \mathrm{s}$. Cool-down was carried out for $10 \mathrm{~min}$, consisting of five minutes of marching $(3.5 \mathrm{~m} / \mathrm{s})$ and five minutes of walking $(1.6 \mathrm{~m} / \mathrm{s})$, with no treadmill slope. The exercise in the walker consisted of $60 \mathrm{~min}$ walking at $1.6 \mathrm{~m} / \mathrm{s}$, comprising 30 min clockwise and 30 min counter-clockwise.
In the maximal-effort tests, performed before and after the six weeks of training, the mares warmed up for $10 \mathrm{~min}$, consisting of five minutes of walking at $1.6 \mathrm{~m} / \mathrm{s}$ and five minutes of marching at $3.5 \mathrm{~m} / \mathrm{s}$, with the treadmill flat. After the warm-up period, the speed was raised to $4 \mathrm{~m} / \mathrm{s}$ and the treadmill was set to a $3^{\circ}$ slope. From this point on, the speed was progressively raised by $1 \mathrm{~m} / \mathrm{s}$ every other minute until the animals could not keep up with the treadmill speed, indicating they had reached fatigue. Next, the mares underwent a 10-min cool-down period, consisting of five minutes of marching $(3.5 \mathrm{~m} / \mathrm{s})$ and five minutes of walking $(1.6 \mathrm{~m} / \mathrm{s})$, with the treadmill remaining at a $3^{\circ}$ slope.

During the tests, the animals wore a heart rate monitor (Equine - Polar ${ }^{\circledR}$ ) to assess this parameter before and after the tests. Before each test, the horses' left jugular vein was cannulated so blood could be collected in the last $15 \mathrm{~s}$ at each speed and at 10, 30, and 60 min into the recovery period.

On test days, the first (baseline) blood sample was collected at $16.00 \mathrm{~h}$ using vacuum blood collection needles (Vacutainer $\mathrm{BD}^{\circledR}$ ) and vacuum tubes with sodium fluoride (Equine - Polar ${ }^{\circledR}$ ) so that the plasma lactate levels were determined. The blood samples were centrifuged at 3,000 rpm for $10 \mathrm{~min}$ to separate the plasma. Next, $1 \mathrm{~mL}$ plasma aliquots were stored in polypropylene Eppendorf tubes and stored at $-18{ }^{\circ} \mathrm{C}$ for further analyses. Plasma lactate level analyses were carried out using a reagent kit (Katal ${ }^{\circledR}$ for lactate and Biosystem $^{\circledR}$ for uric acid) and a spectrophotometer (BTS 315 - Biosystem ${ }^{\circledR}$ ).

During the tests, the animals wore a spirometry mask to measure oxygen intake $\left(\mathrm{VO}_{2}\right)$, carbon dioxide production $\left(\mathrm{VCO}_{2}\right)$, respiratory rate, and tidal volume every $10 \mathrm{~s}$. The aerobic and anaerobic thresholds were determined from these data (Aunola and Rusko, 1988).

The gas analysis system was calibrated before the tests using a gas mixture with $\mathrm{O}_{2}$ and $\mathrm{CO}_{2}$ levels that set the measuring range. Oxygen intake and $\mathrm{VCO}_{2}$ were corrected for normal temperature, pressure, and humidity conditions.

The speed indices at which the heart rate reached 150 beats per minute $(\mathrm{bpm})\left(\mathrm{S}_{150}\right)$ or $200 \mathrm{bpm}\left(\mathrm{S}_{200}\right)$ were estimated through linear regression of the heart rate values as a function of the mares' speed during the tests from the speed of $6 \mathrm{~m} / \mathrm{s}$. The estimates of the speed at which plasma lactate levels reached $2 \mathrm{mmol} / \mathrm{L}\left(\mathrm{SLa}_{2}\right)$ and $4 \mathrm{mmol} / \mathrm{L}$ $\left(\mathrm{SLa}_{4}\right)$, as well as the plasma lactate levels at which the heart rate reached $150 \mathrm{bpm}\left(\mathrm{La}_{150}\right)$ and $200 \mathrm{bpm}\left(\mathrm{La}_{200}\right)$, were obtained though exponential regression of the horses' lactate levels during the progressive steps in each test. The results were subjected to analysis of variance and the means were compared by Fisher's test at 5\% probability using the SISVAR (version 5.0) and SAEG (version 9.1) software. 


\section{Results and Discussion}

No difference $(\mathrm{P}>0.05)$ was found between the Probiotic and Control groups in any of the assessed parameters. However, differences $(\mathrm{P}<0.05)$ were found between the maximal-effort physical tests for time-to-fatigue, aerobic and anaerobic thresholds, $\mathrm{SLa}_{2}, \mathrm{SLa}_{4}$, and $\mathrm{S}_{200}$ (Table 1).

Rezende et al. (2012) did not observe effects of daily supplementation with $20 \mathrm{~g}$ probiotics on physical performance of Andalusian horses subjected to six weeks of training.

In contrast with the results found in present work, Glade and Campbell (1990) observed that a culture of live yeast added to horse diet led to lactate and heart rate reduction in trained animals and suggested that the increased aerobic capacity of supplemented animals was a result of the improvement in nitrogen balance, inducing an increase in muscle mass and metabolic efficiency by increasing muscle vascularity and, consequently, cardiovascular capacity.

The results of the present study also differed from those of Art et al. (1994), who observed an increase in aerobic energy generation in horses supplemented with probiotics. According to Poole and Erickson (2008), better aerobic energy usages were accompanied by improvement in heart response, with increases in $\mathrm{O}_{2}$ supply to the muscles, metabolism and product removal, and were directly related to exercise intensity.

According to Rezende et al. (2012), different responses observed in studies using probiotics in horses may be due to differences in the amount of live yeast supplement given to the animals, as there are no studies suggesting the ideal dose to be used.

A positive influence of the probiotic nutritional effect on horse performance in this study may not have been evidenced because the animals from both groups were trained properly.

Another factor to be considered was that animal diets from both groups were balanced and provided the necessary nutrients for horses undertaking moderate activity (NRC, 2007). If animals were receiving low-fiber and low-nutrient diets, performance would have been affected. It should also be noted that the horses in this study had relatively constant body weight, indicating that dietary energy requirement during the training program was adequately met by adjustments in the diet, following the weekly assessment of animal body conditions. This suspicion agreed with Furtado et al. (2010), who concluded that use of yeast may be beneficial in the diet for horses that are fed a low-quality diet.

The aerobic and anaerobic thresholds, determined both through spirometry and through the lactate levels $\left(\mathrm{SLa}_{2}\right.$ and $\left.\mathrm{SLa}_{4}\right)$, had very similar values. The two methods to determine the aerobic and anaerobic limits have been shown to be appropriate in assessing equine physical performance (Amann et al., 2004). Both in humans and in equines, the anaerobic threshold, determined from lactate, occurs at maximal $\mathrm{VO}_{2}$ percentages similar to the anaerobic threshold determined through spirometry (McDonough et al., 2002).

The training performed at $80 \%$ of the aerobic threshold resulted in the increase of the aerobic and anaerobic thresholds of mares and, consequently, of $\mathrm{SLa}_{2}$ and $\mathrm{SLa}_{4}$. This result showed that the mares gained physical conditioning, which is in line with Castejón et al. (2006), who reported that, during aerobic training, the speed at which the horse starts accumulating lactate in the blood gradually increases, i.e., as conditioning increases, so does $\mathrm{SLa}_{2}$ and $\mathrm{SLa}_{4}$.

Table 1 - Mean spirometric parameters, heart rate, and plasma lactate levels of Mangalarga Marchador mares before and after aerobic training for the Probiotic (Pr) and Control (C) groups and their respective coefficients of variation $(\mathrm{CV})$

\begin{tabular}{|c|c|c|c|c|c|}
\hline \multirow{2}{*}{ Parameter } & \multicolumn{2}{|c|}{ Before training } & \multicolumn{2}{|c|}{ After training } & \multirow{2}{*}{$\mathrm{CV}(\%)$} \\
\hline & $\operatorname{Pr}$ & $\mathrm{C}$ & $\operatorname{Pr}$ & $\mathrm{C}$ & \\
\hline Time-to-fatigue (s) & $600 \mathrm{~b}$ & $644 b$ & $726 a$ & $716 a$ & 5.0 \\
\hline Aerobic threshold $(\mathrm{m} / \mathrm{s})$ & $4.90 \mathrm{~b}$ & $5.00 \mathrm{~b}$ & $5.80 \mathrm{a}$ & $5.50 \mathrm{a}$ & 7.8 \\
\hline Aerobic threshold HR (bpm) & 169 & 180 & 175 & 179 & 8.6 \\
\hline $\mathrm{S}_{150}(\mathrm{~m} / \mathrm{s})$ & 3.90 & 4.30 & 4.60 & 4.40 & 15.5 \\
\hline Lactate $_{150}(\mathrm{~m} / \mathrm{s})$ & 1.63 & 1.87 & 1.47 & 1.50 & 19.6 \\
\hline Anaerobic threshold HR (bpm) & 186 & 188 & 192 & 193 & 8.1 \\
\hline $\mathrm{S}_{200}(\mathrm{~m} / \mathrm{s})$ & $6.20 \mathrm{~b}$ & $6.60 \mathrm{~b}$ & $7.60 \mathrm{a}$ & $7.20 \mathrm{a}$ & 14.3 \\
\hline Lactate $_{200}(\mathrm{~m} / \mathrm{s})$ & 7.20 & 6.81 & 8.43 & 6.50 & 7.5 \\
\hline
\end{tabular}

Means followed by different letters in the rows differ between the physical tests according to Fisher's test $(\mathrm{P}<0.05)$.

$\mathrm{SLa}_{2}$ - speed at which the lactate plasma level reached $2 \mathrm{mmol} / \mathrm{L} ; \mathrm{HR}$ - heart rate; $\mathrm{S}_{150}$ - speed at which HR reached 150 bpm; Lactate ${ }_{150}$ - lactate level at the speed at which HR reached $150 \mathrm{bpm} ; \mathrm{SLa}_{4}$ - speed at which the plasma lactate level reached $4 \mathrm{mmol} / \mathrm{L} ; \mathrm{S}_{200}$ - speed at which $\mathrm{HR}$ reached $200 \mathrm{bpm}$; Lactate ${ }_{200}$ - lactate level at the speed at which $\mathrm{HR}$ reached $200 \mathrm{bpm}$. 
In the after-training test, the mares reached the highest speed when the heart rate was $200 \mathrm{bpm}\left(\mathrm{S}_{200}\right)$, agreeing with Rogers et al. (2007), who found that $S_{200}$ is sensitive to the improvement in training and represents one of the most widely used variables to estimate the anaerobic threshold. However, the authors point out that these values have been higher than the anaerobic threshold determined through spirometry or based on lactate $\left(\mathrm{SLa}_{4}\right)$, which was also found in the present study.

On the other hand, no difference $(\mathrm{P}>0.05)$ was found regarding the speeds at which the mares reached $150 \mathrm{bpm}$ heart rate $\left(\mathrm{S}_{150}\right)$ (Table 1). The values of speed at $150 \mathrm{bpm}$ represented $84 \%$ of the aerobic threshold $\left(\mathrm{SLa}_{2}\right)$ in the pre-training test and $79 \%$ in the after-training test, which shows that at $150 \mathrm{bpm}$ the mares were at a speed that characterized eminently aerobic exercise. Heart rate is strongly correlated with speed in maximal exercises, but weakly correlated with low- and medium-intensity exercise (Babusci and López, 2007). Evans (2004) showed that the heart rate during trot and canter may greatly vary due to the interference of psychogenic factors and its response to the exercise intensity is not linear.

No difference was found $(\mathrm{P}>0.05)$ in the plasma lactate levels when the mares' heart rate was 150 and $200 \mathrm{bpm}$ both before and after training (Table 1). Nevertheless, the speed at which the mares reached $200 \mathrm{bpm}$ heart rate was higher in the pre-training test while maintaining the same lactate levels. This result shows that plasma lactate deposition after training was lower in more intense exercises.

The plasma lactate levels at the moment when the mares reached $150 \mathrm{bpm}$ heart rate were low, close to baseline values (Table 1). This shows that the production and elimination of lactate were balanced at that moment and, therefore, no lactate accumulated in the muscle, which indicates that the exercise was eminently aerobic, matching the result of the $\mathrm{S}_{150}$ variable.

No difference $(\mathrm{P}>0.05)$ was found in the lactate levels at maximal speed both before and after training and also at 10 and $60 \mathrm{~min}$ into the recovery period (Table 2). In the after-training test, the plasma lactate level was higher than in the test before training only at $30 \mathrm{~min}$ into the recovery period.

Although lactate at maximal speed did not differ $(\mathrm{P}>0.05)$, in the after-training test the mares reached higher speeds, which resulted in a higher time-to-fatigue (Table 1). This may indicate that lactate accumulated more slowly in the blood after training, matching the increases in the aerobic and anaerobic thresholds and allowing the mares to work longer and faster.

Regarding the similarity in lactate levels at $10 \mathrm{~min}$ of the recovery period, because the tests were performed at maximal effort, the mares reached maximal lactate levels. This fact, associated with the longer time-to-fatigue in the after-training test, might be responsible for the similarity in maximum lactate levels in the tests before and after training at $10 \mathrm{~min}$ of recovery.

McGowan et al. (2002) correlated horse blood lactate levels after exercise with the time running on the treadmill $(r=0.71)$. In the present study, even though the mares exercised for longer and faster in the after training test, the plasma lactate levels at 10 and $60 \mathrm{~min}$ of recovery were the same.

Since the mares performed greater effort during the after-training test, the lactate metabolization rate may have been slower, which justifies the difference in lactate levels at $30 \mathrm{~min}$ into the recovery period.

No difference $(\mathrm{P}>0.05)$ was found in the maximal heart rate and at 10, 20,30,60, and $120 \mathrm{~min}$ after training (Table 3).

Similarly to lactate, the longer time-to-fatigue in the after-training test (Table 1) may be responsible for the similar values in maximum heart rate and during the recovery period, since, according to Evans (2004), training promotes an increase in the speed at which $\mathrm{HR}_{\max }$ is reached. Thus, the cardiovascular system adapted to the greater physical activity by the skeletal muscle and to the metabolic demand during the after-training test by readjusting the blood flow so as to increase the availability of oxygen and energetic substrates for the synthesis of adenosine triphosphate (ATP), which is in line with Babusci and López (2007).

Table 2 - Mean maximum lactate levels $\left(\right.$ Lactate $_{\max }$ ) and lactate levels at 10, 30, and 60 min after exercise by Mangalarga Marchador mares before and after aerobic training in the Probiotic (Pr) and Control (C) groups, with their respective coefficients of variation $(\mathrm{CV})$

\begin{tabular}{|c|c|c|c|c|c|}
\hline \multirow{2}{*}{ Parameter } & \multicolumn{2}{|c|}{ Before training } & \multicolumn{2}{|c|}{ After training } & \multirow{2}{*}{ CV $(\%)$} \\
\hline & $\operatorname{Pr}$ & $\mathrm{C}$ & $\operatorname{Pr}$ & $\mathrm{C}$ & \\
\hline Lactate $_{\max }(\mathrm{mmol} / \mathrm{L})$ & 16.5 & 13.7 & 17.1 & 15.4 & 3.9 \\
\hline Lactate $10^{\prime}(\mathrm{mmol} / \mathrm{L})$ & 14.8 & 12.6 & 16.6 & 16.2 & 20.7 \\
\hline Lactate $30^{\prime}(\mathrm{mmol} / \mathrm{L})$ & $9.2 b$ & $7.4 \mathrm{~b}$ & $11.3 \mathrm{a}$ & $10.1 \mathrm{a}$ & 4.8 \\
\hline Lactate $60^{\prime}(\mathrm{mmol} / \mathrm{L})$ & 3.7 & 3.6 & 5.7 & 4.7 & 38.8 \\
\hline
\end{tabular}

Means followed by different letters in the rows differ between the physical tests according to Fisher's test $(\mathrm{P}<0.05)$. 
Table 3 - Mean maximum heart rate $\left(\mathrm{HR}_{\max }\right)$ and heart rate $(\mathrm{HR})$ at 10, 30, 60, and 120 min after exercise by Mangalarga Marchador mares before and after aerobic training in the Probiotic (Pr) and Control (C) groups, with their respective coefficients of variation $(\mathrm{CV})$

\begin{tabular}{|c|c|c|c|c|c|}
\hline \multirow{2}{*}{ Parameter } & \multicolumn{2}{|c|}{ Before training } & \multicolumn{2}{|c|}{ After training } & \multirow{2}{*}{$\mathrm{CV}(\%)$} \\
\hline & $\operatorname{Pr}$ & $\mathrm{C}$ & $\operatorname{Pr}$ & $\mathrm{C}$ & \\
\hline $\mathrm{HR}_{\text {max }}(\mathrm{bpm})$ & 226 & 223 & 230 & 226 & 4.3 \\
\hline HR 10' (bpm) & 127 & 120 & 120 & 120 & 18.3 \\
\hline HR 30' (bpm) & 88 & 84 & 87 & 80 & 32.8 \\
\hline HR 60’ (bpm) & 56 & 56 & 62 & 65 & 25.6 \\
\hline HR 120' (bpm) & 43 & 42 & 44 & 43 & 18.0 \\
\hline
\end{tabular}

\section{Conclusions}

Supplementation with Saccharomyces cerevisiae has no effect on the physical conditioning of Mangalarga Marchador mares. The aerobic training protocol adopted raises the aerobic and anaerobic capacity of Mangalarga Marchador mares.

\section{Acknowledgments}

The authors thank Universidade Federal de Minas Gerais, Coordenação de Aperfeiçoamento de Pessoal de Nível Superior (CAPES/PROCAD), Conselho Nacional de Desenvolvimento Científico e Tecnológico, Escola de Equitação do Exército, Universidade Federal Rural do Rio de Janeiro, Associação Brasileira de Criadores de Cavalo Mangalarga Marchador, Rações Itambé, BET Laboratories, Lesaffre do Brasil, Hertape Calier, and Haras Santorini.

\section{References}

Amann, M.; Subudhi, A. W.; Walker, J.; Eisenman, P.; Shultz, B. and Foster, C. 2004. An evaluation of the predictive validity and reliability of ventilatory threshold. Medicine \& Science in Sports \& Exercise 36:1716-1722.

Art, T.; Votion, D.; McEntee, K.; Amory, H.; Linden, A.; Close, R. and Lekeux, P. 1994. Cardio-respiratory, hematological and biochemical parameter adjustments to exercise: Effect of a probiotic in horses during training. Veterinary Research 25:361-370.

Aunola, S. and Rusko, H. 1988. Comparison of two methods for aerobic threshold determination. European Journal of Applied Physiology 57:420-424.

Babusci, M. and López, E. F. 2007. Sistema cardiovascular. p.123-132. In: Fisiologia del ejercicio em equinos. 1.ed. Boffi, F. M., ed. Inter-Médica, Buenos Aires.

Boffi, F. M. 2007. Principios de entrenamiento. p.223-241. In: Fisiologia del ejercicio em equinos. 1.ed. Boffi, F. M., ed. Inter-Médica, Buenos Aires.

Castejón, F.; Trigo, P.; Muñoz, A. and Riber, C. 2006. Uric acid responses to endurece racing and relationships with performance, plasma biochemistry and metabolic alterations. Equine Veterinary Journal 36:70-73.

CEPEA - Centro de Estudos Avançados em Economia Aplicada. 2006. Estudo do complexo do agronegócio cavalo no Brasil. CNA/MAPA, Brasília.

Evans, D. L. 2004. Exercise testing in the field. p.19-31. In: Hinchcliff, K. W.; Kaneps, A. J. and Geor, R. J., eds. Equine sports medicine and surgery. Saunders, Philadelphia.

FAO - Food and Agriculture Organization of the United Nations. FAO Statistics Division 2010. Available at: $<\mathrm{http} / /$ :faostat.fao.org/ site/573/DesktopDefaut.aspx?PageID=573\#ancor $>$ Accessed on: Jan. 3, 2012

Glade, M. J. and Campbell, T. M. 1990. Effects of dietary yeast culture supplementation during the conditioning period on equine exercise physiology. Equine Veterinary Science 10:434-443.

McDonough, P.; Kindig, C. A.; Ramsel, C.; Poole, D. C. and Erickson, H. H. 2002. The effect of treadmill incline on maximal oxygen uptake, gas exchange and metabolic response to exercise in the horse. Experimental Physiology 87:499-506.

McGowan, C. M.; Golland, L. C.; Evans, D. L.; Hodgson, D. R. and Rose, R. J. 2002. Effects of prolonged training, overtraining and detraining on skeletal metabolites and enzymes. Equine Veterinary Journal 34(Suppl.):257-263.

Moura, R. S.; Saliba, E. O. S.; Almeida, F. Q.; Lana, A. M. Q.; Moreira, D. C. A.; Silva, V. P.; Moss, P. C. B.; Pereira, R. V. G.; Costa, M. L. L. and Rezende, A. S. C. 2011. Digestibilidad aparente de dietas con probióticos o fitasa para potros Mangalarga Marchador. Archivos de Zootecnia 60:193-203.

Moura, R. S.; Saliba, E. O. S.; Almeida, F. Q.; Lana, A. M. Q.; Silva, V. P. and Rezende, A. S. C. 2009. Feed efficiency in Mangalarga Marchador foals fed diet supplemented with probiotics of phytase. Revista Brasileira de Zootecnia 38:1045-1050.

NRC - National Research Council. 2007. Nutrient requirements of horses. National Academy Press, Washington, DC.

Poole, D. C. and Erickson, H. H. 2008. Cardiovascular function and oxygen transport: responses to exercise and training. p.212-245. In: Equine exercise physiology: the science of exercise in the athletic horse. Hinchcliff, K.W.; Geor, R. J. and Andris, J. K., eds. Saunders, Philadelphia

Rezende, A. S. C.; Trigo, P.; Lana, A. M. Q.; Santiago, J. M.; Silva, V. P. and Castejón, F. 2012. Yeast as a feed additive for training horses. Ciência e Agrotecnologia 36:354-362.

Rogers, C. W.; Rivero, J. L. L.; van Breda, E.; Lindner, A. and Sloet van Oldruitenborgh-Oosterbaan, M. M. 2007. Describing workload and scientific information on conditioning horses. Equine Comparative Exercise Physiology 4:1-6. 